\title{
Against Aesthetic/Sensory Dependence
}

\author{
Jiri Benovsky
}

\begin{abstract}
A в STRACT In his book The Metaphysics of Beauty (2001) Nick Zangwill argues for the claim that aesthetic properties metaphysically necessarily depend on sensory properties. This claim plays a role in his argument against physicalist aesthetic realism as well as in the formulation of his own response-dependence view. In this article, I offer reasons to resist the aesthetic/ sensory dependence claim by a discussion of the case of theories, theorems, proofs, and similar theoretical objects, which do possess genuinely aesthetic properties, while these do not depend on any sensory properties. I argue against Zangwill's claim that such attributions of aesthetic properties are merely metaphorical.

KEYWORDS Aesthetic/sensory dependence, Aesthetic realism, Metaphysics of beauty, Beauty of theoretical objects
\end{abstract}

\section{1}

In his excellent book The Metaphysics of Beauty ${ }^{1}$ Nick Zangwill presents an elaborated argument against physicalist aesthetic realism with the following overall structure:

Premise 1: Aesthetic properties metaphysically necessarily depend on sensory properties. ${ }^{2}$

Premise 2: Sensory properties are not mind-independent. ${ }^{3}$

Therefore: Since aesthetic properties inherit the metaphysical status of sensory properties, and so are not mind-independent, physicalist aesthetic realism is false. ${ }^{4}$

Physicalist aesthetic realism is the claim that mind-independent objects in the world (can) have aesthetic properties independently of what anybody thinks - i.e. aesthetic properties are mind-independent. I think that Zangwill is right to reject this claim. However, in this article, I am not interested in the conclusion of the argument, but in its Premise 1, namely, the claim that aesthetic properties necessarily depend on sensory properties. For even though I share the argument's conclusion, I will argue that this premise is false, and so the argument does not go through. This has a consequence not only for us who want to reject physicalist aesthetic realism. The idea behind Premise 1 actually plays an important role in Zangwill's own view as well: He defends a version of the view that aesthetic properties are response-dependent, and that "the responses that aesthetic properties depend on are [...] sensory responses." Here again, even if at 
the end of the day I would also like to embrace a response-dependence view of aesthetic properties, I think that the aesthetic/sensory dependence claim is incorrect, and so it cannot be used in the defence or in the formulation of this view.

So it is in a spirit of tough love that, in this article, I will argue against the aesthetic/sensory dependence claim. In order to do so, I will focus on counter-examples to this claim such as the beauty of theories, proofs, and theorems. In short, I will defend the claim that theories - and the like do possess genuine aesthetic properties, where these do not depend on any sensory properties. (Perhaps, a list of other counter-examples could include ideas, concepts, abstract structures, or God [under the assumption that we do not have sensory experiences of God].)

\section{2}

Here is how Zangwill formulates the aesthetic/sensory dependence thesis: "I shall defend a weak dependence thesis: Aesthetic properties depend in part on sensory properties, such as colors and sounds. Just as something has moral properties only if it has mental properties, so, according to the weak dependence thesis, aesthetic properties are properties that something has only if it has sensory properties. [...] The thesis is not the strong thesis that the aesthetic properties of a thing depend only on its sensory properties. The thesis is that sensory properties are necessary for aesthetic properties, not that they are sufficient. [...] [W]ithout sensory properties, there would be no aesthetic properties."

Put in these terms, what I will argue for is that sensory properties are neither sufficient nor necessary for aesthetic properties. In order to better understand Zangwill's claim, let us illustrate it by what he says about the beauty of literature. There is, of course, "the music of words" of a poem or a novel, and these are sensory properties of a literary work. But one could claim that these are not the relevant properties. Rather, it can be thought, the semantic properties of a literary work are those that matter - this is the content of the work. If this is so, since these semantic properties are not sensory properties, literature is a counter-example to the aesthetic/sensory dependence thesis. Zangwill replies that while of course there can be great value in the semantic content of a literary work, it is not an aesthetic value. Not every value of a novel or a poem is an aesthetic value. As he says, a novel can be clever, inspiring, or moving, via its semantic content, but these are other than aesthetic values. If a novel has aesthetic properties at all, Zangwill claims, they "derive from the particular choice of words, because of the way they sound."7 Zangwill makes 
here a distinction between aesthetic value and artistic value: Originality, for instance, is said to be an artistic value, but not an aesthetic one ${ }^{8}$ - in general, artistic value is a broader category, including aesthetic value as one of its components. ${ }^{9}$

The case of literary works is highly relevant. Firstly, it is very useful in order to get a better understanding of what the aesthetic/sensory dependence claim amounts to - we can really see it at work here. Secondly, and importantly, the treatment Zangwill provides of this case can be doubted for the same reasons we will have to doubt the case of theories and the like. The reason why I will focus on theories rather than novels lies in the fact that counter-examples such as a metaphysical theory or a mathematical proof cannot be said to possess anything like a "music of words." Their formulation is often very "non-musical," often formal, and there is nothing like the particular choice of words that can play any significant role here "because of the way they sound." Thus, they are sharper counter-examples than novels: In the case of novels, it is always possible for the defender of the aesthetic/sensory dependence thesis to claim that their beauty comes from the "music of words," while this strategy is just not available in the case of theories, theorems, or proofs. The defender of the dependence thesis has then only one option available to him - namely to claim that such objects are not (and cannot be) beautiful at all, that they do not (and cannot) possess aesthetic properties at all. Since there is nothing relevantly sensory in the way such objects are experienced/grasped by us, unlike in the case of novels, theories then either cannot possess aesthetic properties at all and do not constitute a counter-example to the aesthetic/sensory dependence thesis, or they can and the thesis is false.

As we will see, there are reasons to think that theories, theorems, and proofs do possess genuinely aesthetic properties. If this is true, and if as a consequence the aesthetic/sensory dependence thesis fails, then, since it has to be abandoned anyway, it could/should perhaps also be abandoned in the case of novels, which would allow us to accept that semantic content of a literary work can exhibit genuinely aesthetic properties as well.

\section{3}

The reason I will offer to think that theories, theorems, proofs, or particular steps in proofs ${ }^{10}$ can possess genuine aesthetic properties is simple: They have all the typical features that objects that we typically claim to possess aesthetic properties have. They can exhibit features such as unity, simplicity, harmony, and symmetry (see below), they have the capacity to 
cause passion (or other responses), they are "fitted to give a pleasure and satisfaction to the soul."11 Importantly, they are often said and judged to be beautiful (or not). W. V. Quine is among the most famous examples: "Wyman's overpopulated universe is in many ways unlovely. It offends the aesthetic sense of us who have a taste for desert landscapes [...]."12 Quine is far from being alone in attributing aesthetic properties to theories. Almost every conference or colloquium contains such examples, where a theory, a theorem, or a philosophical argument is labelled as being beautiful or elegant (or not). This is no mere loose speaking during a talk, one finds such attributions of aesthetic properties to theories seriously expressed in published work. Here are two examples, one from physics: "The foundations of the [general relativity] theory are, I believe, stronger than what one could get simply from the support of experimental evidence. The real foundations come from the great beauty of the theory. [...] It is the essential beauty of the theory which I feel is the real reason for believing in it,"13 and one from metaphysics: "It is easy to feel [...] an intellectual joy in contemplating a theory so elegant and beautiful as four-dimensionalism, and it is tempting to accept the theory simply on this basis, utilizing arguments to rationalize more than justify." ${ }^{14} \mathrm{On}$ the one hand, such statements of course do not constitute any kind of proof of the fact that theories and the like do possess genuinely aesthetic properties, but on the other hand such statements by serious practitioners seem at the very least to indicate that there is nothing wrong with the idea that they might.

To have an example in mind, consider the bundle-bundle-bundle theory. ${ }^{15}$ I mention it here because I think that it nicely illustrates the first point stated above, namely the idea that theories (but also theorems, proofs, and the like) can exhibit features such as symmetry, harmony, and unity. Let us focus on its structure. According to the bundle-bundle-bundle theory, (i) ordinary material objects are bundles of properties (this is the first level of bundling), (ii) ordinary objects persist through time by having temporal parts, which means in this case that they are temporally extended bundles of the bundles that are the temporal parts (this is the second level of bundling), and (iii) ordinary objects have their modal properties in a way similar in which they have temporary properties, that is, by having modal parts - in short, by being bundles of all of their modal counterparts (this is the third level of bundling). One may like this view or one may dislike it for many different theoretical reasons, but I think that it is undeniable that the theory's structure possesses a kind of elegant symmetry, unity, and harmony that makes it very beautiful, 
where these features lie in the fact that it appeals to the same notion of bundling to solve three different issues in the same way. It provides the same solution to three different puzzles: The problem of the nature of material objects, the problem of their persistence through time, and the problem of de re modality. One can then see this theory as being an abstract structure that is balanced, symmetrical, and harmonious, and that has a kind of unity that lies in the fact that the same notion is being used in different places to solve different problems. Here is an illustration of what this abstract structure could look like when schematically represented on paper (on this figure, a person named "Cyrano" has, in the actual world, a big nose at $t_{1}$, but he then undergoes plastic surgery and has a small nose at $t_{2}$ and $t_{3}$; in another possible world, Cyrano has a small nose all along):

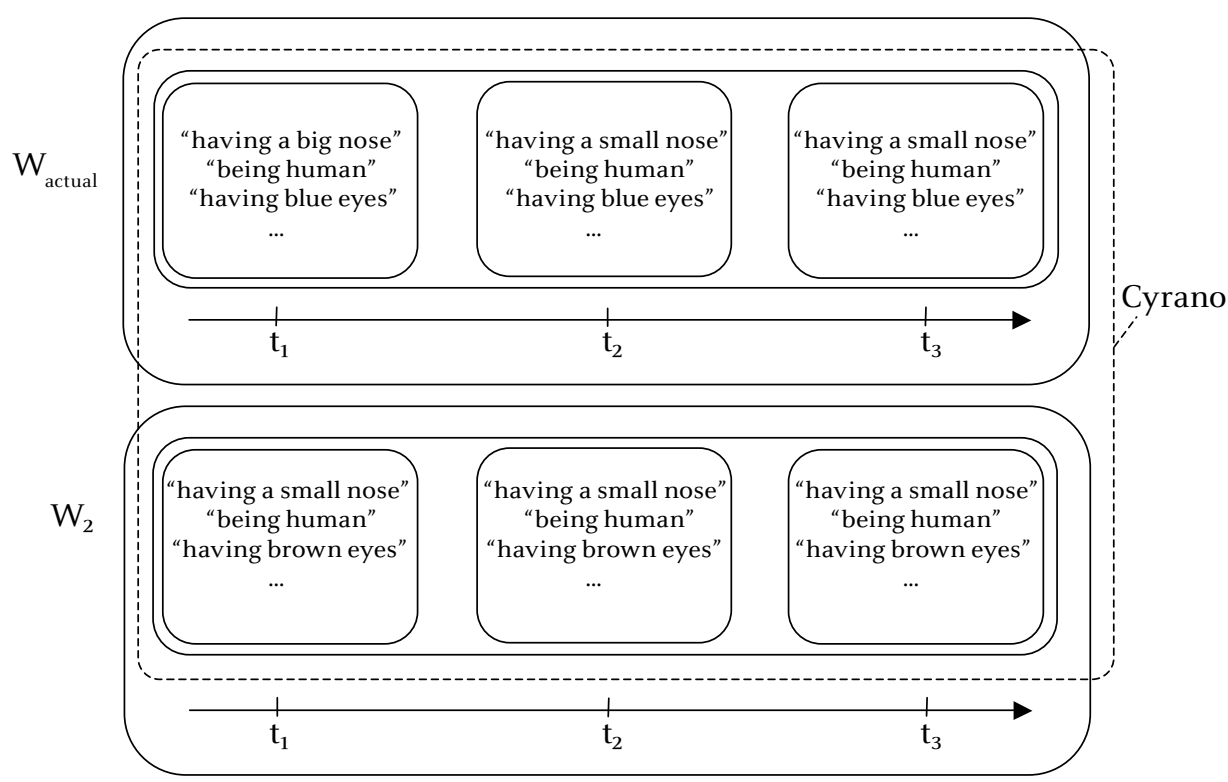

In addition to the fact that theories can possess features such as symmetry, harmony, and unity, and to the fact that they are often judged to be beautiful, it is also the case when it comes to theories and the like that, as in the case of typical works of art such as paintings or symphonies, their aesthetic properties can be said to be grounded ${ }^{16}$ in their non-aesthetic properties such as (i) internal consistency, (ii) explanatory power, (iii) simplicity, (iv) parsimony, (v) preservation of our intuitions, or (vi) compatibility with other (philosophical and/or scientific) theories, to cite only the most common ones. To compare theories to paintings, for 
instance, such properties are akin to color distribution on a canvas, the thickness and quality of the paint, the way it was placed on the canvas using brushes in such-and-such a way, and so on. These non-aesthetic features of theories are subject to controversies, they are weighted, evaluated, and attributed (or not) to the theories at hand, exactly as we can evaluate and appreciate non-aesthetic features of paintings and symphonies - precisely in order to attribute aesthetic properties to them.

Such attributions of aesthetic properties to theories (and the like) are also, exactly as in the case of "typical" works of art, context-dependent. Most artworks such as paintings or novels get a part of their aesthetic value from the context in which they were created. The first cubist paintings have great value precisely because they were the first. Milan Kundera's novels written before 1989 get a part of their beauty from the political and historical context in which they were written. Of course, these are controversial claims in the eyes of the friend of the aesthetic/sensory dependence thesis, since he could argue that these values are not aesthetic values. But this is not really the point I want to focus on here and now - I am not arguing for or against the claim of context-dependence (even though I am strongly sympathetic to it). The point here is that in both cases - that is, whether one accepts the context-dependence claim or not - one can hold the same claim when it comes to theories and the like. The context-dependence idea, if one accepts it, is simply that not only intrinsic properties of an object are relevant. Of course, they are colors and shapes are central when it comes to paintings, for instance. But these are not the only relevant non-aesthetic properties of an object in which its aesthetic properties are grounded. Some extrinsic relational properties also need to be taken into account. Arguably, the context of creation of an artwork plays this role (see, inter alia, Kendall Walton, ${ }^{17}$ or Jerrold Levinson. ${ }^{18}$ ) Imagine two indistinguishable paintings that are qualitatively indiscernible - they are exact duplicates that consist of the same arrangements of paint. The idea here is then that they could still have different aesthetic properties depending, say, on the time at which they were created.

Again, the role context plays in the having of aesthetic properties is of course controversial, but were it to be accepted in the way suggested above, the same idea could then be applied in the case of theories, perhaps even more obviously. Regarding scientific or philosophical theories, the context in which they were created matters greatly, the relevant context being the state of scientific or philosophical knowledge at the time of the formulation of the theory. Ptolemy's theory of the movement of 
planets was, at its time of creation, a tremendous achievement in systematic thought and careful observation. In this context, given the state of astronomical knowledge in the 2nd century, there is no doubt that Ptolemy's epicyclic model was highly beautiful and elegant (to anticipate the conclusion that theories do possess aesthetic properties), and had great value. Not so much today, if evaluated from today's standards: There are now simpler, more efficient views with greater explanatory power, greater compatibility with other scientific theories, etc. (remember the incomplete list of the (i)-(vi) non-aesthetic properties that theories possess and in which their aesthetic properties - if they have any - are grounded). The (rather trivial) point is: Exactly as in the case of works of art, when it comes to evaluation of theories, context of creation can be seen to matter.

Another similarity between typical artworks and theories lies in the role of the evaluator - his taste. Indeed, one can argue that not only the context of creation of an artwork has to be included in the basis in which its aesthetic properties are grounded, but that the taste of the evaluator has to be included as well. The notion of "taste" is here a rather technical one, and does not amount to a mere the first thing that comes to mind liking. Rather, the taste that one can think to count here is a capacity of a trained evaluator to discern the aesthetic properties of an objects, as for instance Sibley remarks: "When I speak of taste [...], I shall not be dealing with questions which center upon expressions like 'a matter of taste' (meaning, roughly, a matter of personal preference or liking). It is with an ability to notice or discern things that I am concerned." ${ }^{19}$ Thus, taste is understood here as a rather sophisticated capacity, which is in line with what David Hume thought when he said that not everybody's taste counts, ${ }^{20}$ and that not everybody is a good critic of art. As above in the case of the role context plays, when it comes to taste as I shortly described here, its role is controversial. But here again, what matters mostly for my argument is that if one thinks that taste does play such a role, it can then very well play this role in the situation in which we find ourselves when it comes to theories, proofs, arguments, or theorems - it is more than obvious that only a trained specialist can discern and weight the non-aesthetic properties of such objects, and only such a competent evaluator can then use his taste to make a claim about their beauty (think of Quine's "desert landscapes"). But not only this, since being an expert is not the same thing as having taste. Being an expert is here a necessary condition, but not a sufficient one. (To have an example in mind, perhaps the kind of "incredulous stare" that is many colleagues' reaction to David Lewis' modal realism is an expression of the idea that while Lewis is a 
great expert, he has poor taste.) Thus, perhaps even more clearly than in the case of works of art such as paintings, novels, or symphonies, it is true to say that in the case of theories and the like only attributions of aesthetic properties by trained, qualified, and competent specialists, who have a "good sense" as Hume puts it, ${ }^{21}$ count. These attributions and judgments are then part of what aesthetic properties of such objects can be grounded in.

\section{4}

In the preceding section, we have seen that theories, theorems, proofs, and the like behave a lot like typical works of art such as paintings, symphonies, or novels:

- They can exhibit features such as unity, simplicity, harmony, and symmetry.

- They can cause appropriate responses (emotional or other) in their evaluators.

- They are often said and judged to possess aesthetic properties by competent scientists and philosophers.

- They possess relevant non-aesthetic features in which the having of aesthetic properties can be grounded.

- The context of their creation matters, as well as the taste of competent evaluators.

Thus, I submit, theories and the like have all it takes to be able to have aesthetic properties. There is just no reason to think the opposite. In the relevant sense, they behave exactly like works of art do. The only reason to resist the idea that they can genuinely possess aesthetic properties would be to say that they violate the aesthetic/sensory dependence thesis, but that would be question-begging.

\section{5}

Zangwill himself rejects any attributions of aesthetic properties to theories or theorems because he takes such attributions to be merely metaphorical. Again, a comparison with what he says about novels is useful:

Contents have purely structural properties. The Odyssey, for example, has a harmoniously proportioned overall construction. [...] It might be suggested that we can appreciate such structures in themselves, in the way that we appreciate the temporal structure of a piece of music or the visual structure of an abstract pattern. [But w] hen we value structural properties of content, it is because of its 
role in the presentation of a story which has an independent moral, political, religious, or emotional appeal. So if we use words like "beautiful" and "elegant" to describe properties of a plot, that use is metaphorical. ${ }^{22}$

He then mentions the case of theories and the like and asks: "But why should we agree that the properties we appreciate here are aesthetic ones? There are intellectual pleasures, of course, but that should not encourage us to deem these pleasures aesthetic pleasures." ${ }^{23}$ Thus, he accepts that theories or theorems are often said and judged to possess aesthetic properties by competent scientists and philosophers, but he claims that such attributions and judgments of aesthetic properties are merely metaphorical. The reason he provides to think that this is so is that such theoretical objects have a purpose. Theories, theorems, and proofs are here to accomplish something, they are created to do some scientific work. They are not, as I understand Zangwill, created to be beautiful, they are created with something completely different in mind - perhaps something like scientific truth. Suppose that this is so. ${ }^{24}$ But why does having a purpose prevent anything from being able to possess aesthetic properties? Many traditional craftsman tools are built for a reason and with a purpose, but many of them are genuinely beautiful works of art themselves. My laptop computer is a very elegant thing as well. Having a purpose certainly does not prevent anything from being beautiful. Furthermore, having a purpose and fulfilling it in an efficient and elegant way can itself be beautiful - a craftsman tool's simplicity and elegant efficiency is something to be aesthetically appreciated. The same, I submit, is true of theories - the way they do their work, the simplicity and parsimony, say, with which they are able to explain some complex phenomena, is exactly what one can find genuinely beautiful about them. (And, precisely because of the way they accomplish their purpose, they certainly are "fitted to give a pleasure and satisfaction to the soul," as Hume ${ }^{25}$ puts it).

To come back to the claim that any such attributions of aesthetic properties to theories are metaphorical, Zangwill says, when it comes to scientific theories, that a theory could not be said to be beautiful if it did not explain the data. This is why he says that we only metaphorically say that it is beautiful while what we are doing is just to appreciate that it explains a lot of data in an efficient way. One way to resist this claim is to remember the case of Ptolemy. When evaluated from today's point of view, his theory of the motion of planets certainly does not explain the data and certainly is not very efficient. But it still can, I submit, be found beautiful. It has a beautiful structure, it has an elegant and sophisticated 
way of accomplishing its task, it aims at simplicity and harmony - in short, it has many of the non-aesthetic features in which aesthetic properties can be grounded. Take another example, a contemporary one: very few philosophers accept that David Lewis's modal realism is true and that it really works as an acceptable metaphysics of modality. But this does not take away the theory's beauty and elegance, probably grounded in its simplicity, straightforwardness, and boldness. If you have a certain taste (qualitative rather than quantitative) for desert landscapes, you will be struck by the theory's beauty in a very clear way.

So, why insist that attributions of aesthetic properties to theories and the like are merely metaphorical? Again, one could think so precisely because it would be at tension with the aesthetic/sensory dependence principle, but that would be question-begging. In Zangwill's own terminology, one could perhaps want to say that theories and the like merely have artistic value, but not aesthetic value (see $\mathbb{2}$ above), but there does not seem to be a (non-question-begging) reason for such a claim - there just does not seem to be a reason to discard the aesthetic properties of such theoretical objects as being genuinely aesthetic. When we appreciate, say, a structure of a theory (or a novel, for that matter), we are not just appreciating the role it plays in how the theory manages to explain the data in order to get to a scientific or philosophical truth (or the role it plays in the story which has an independent moral, political, religious, or other appeal). We can appreciate it for itself, for how elegantly structured it is, for how nicely it makes things fit together, or for the baroque complexity it can have (if you have a taste for the baroque rather than for desert landscapes).

Thus, I submit that scientific and philosophical theories, theorems, proofs and similar can possess genuinely aesthetic properties. They have all it takes to be able to have them. How do we come to the conclusion that paintings, say, can have aesthetic properties? First, they have nonaesthetic properties in which their aesthetic properties can be grounded (such-and-such a distribution of paint on a canvas, for instance), and these can be discussed from many points of view, their merits can be weighted and debated, and so on. Thus, paintings can exhibit symmetry, harmony, unity, as well as many other non-aesthetic relevant features. Second, they can produce relevant responses in their spectators. These can be emotional, intellectual, or other - and by all means they are "fitted to give a pleasure and satisfaction to the soul". Third, they are often said and judged to possess aesthetic properties by competent judges. Fourth, the context of their creation matters. Fifth, the taste of the competent 
evaluator matters. These - and perhaps other - are the criteria that make us say that paintings can have aesthetic properties. And as we have seen theories and the like do satisfy all of these criteria as well. This is why I think we should say that they can possess genuinely aesthetic properties as well.

\section{Notes}

1. Nick Zangwill, The Metaphysics of Beauty (Ithaca, NY: Cornell University Press, 2001).

2. Ibid., chap. 8 and 11. See also Nick Zangwill, "Aesthetic/Sensory Dependence," British Journal of Aesthetics 38 (1998), 66-81.

3. Zangwill, The Metaphysics of Beauty, chap. 11.

4. Ibid.

5. Ibid., 200.

6. Ibid., 127.

7. Ibid., 137.

8. Ibid., 108.

9. See Zangwill, "Aesthetic/Sensory Dependence," 74-75, and The Metaphysics of Beauty, 11, 58, 137.

10. G.C. Rota takes such steps to be the best examples of mathematical beauty. See G.C. Rota, "The Phenomenology of Mathematical Beauty," Synthese 111 (1997), 171-82.

11. As David Hume puts it, cf. David Hume, A Treatise of Human Nature, edited by L. A. Selby-Bigge, 2nd ed. revised by P. H. Nidditch (Oxford: Clarendon Press, 1975), 299.

12. W. V. Quine, "On What There Is," Review of Metaphysics 2 (1948), 22.

13. Paul A. M. Dirac, "The Excellence of Einstein's Theory of Gravitation," in Einstein: The First Hundred Years, eds. Maurice Goldsmith, Alan Mackay and James Woudhuysen (Oxford: Pergamon Press, 1980), 10.

14. Theodore Sider, Four Dimensionalism: An Ontology of Persistence and Time (Oxford: Oxford University Press, 2001), 74.

15. For a detailed discussion of this view, see Jiri Benovsky, "A Modal Bundle Theory," Metaphysica 7, no. 2 (2006), 21-35.

16. Grounding captures better what we want to say here than supervenience. For a detailed defense of this claim, see Jiri Benovsky, "Aesthetic Supervenience vs. Aesthetic Grounding," Estetika: The Central European Journal of Aesthetics 49, no. 2 (2012), 166-78.

17. Kendall Walton makes a distinction between narrow and broad non-aesthetic properties of objects, in which its aesthetic properties are grounded. The 
Jiri Benovsky

narrow properties are the intrinsic ones, like colors and shapes, and the broad properties are the relational ones, like, precisely, the context in which an object was created. See Kendall Walton, "Categories of Art," Philosophical Review 79 (1970).

18. Jerrold Levinson, "Aesthetic Supervenience," Southern Journal of Philosophy 22, Supplement (1984), 93-94.

19. Frank Sibley, "Aesthetic Concepts," Philosophical Review 68 (1959), 423.

20. David Hume also adds that such qualified judges also have to be practiced in the attribution of aesthetic properties, have to have a "good sense," and have to be intellectually honest. Cf. David Hume, "On the Standard of Taste," in Essays: Moral, Political, and Literary (Indianapolis: Liberty Classics, 1985), 240-41.

21. See footnote 20.

22. Zangwill, The Metaphysics of Beauty, 139-40, my italics.

23. Ibid., 140.

24. In my book Meta-metaphysics, I offer reasons to doubt that, but I shall not press this point here. See Jiri Benovsky, Meta-metaphysics: On Metaphysical Equivalence, Primitiveness, and Theory Choice (New York: Springer, 2016).

25. Hume, A Treatise of Human Nature, 299. 